\title{
APRENDER E ENSINAR NO ENSINO MÉDIO: INTERFACES COM A INDISCIPLINA ESCOLAR
}

\author{
DANIELI VIECELI* \\ Instituto Federal Catarinense - IFC - Videira (SC) \\ danieli.vieceli@ifc.edu.br
}

MARIA TERESA CERON TREVISOL

Universidade do Oeste de Santa Catarina mariateresa.trevisol@unoesc.edu.br

\begin{abstract}
RESUMO
O presente trabalho tem por objetivo analisar a compreensão dos estudantes do ensino médio integrado de uma instituição federal de ensino a respeito do fenômeno da indisciplina no âmbito escolar. A pesquisa se caracteriza como de cunho exploratório, de natureza qualitativa, de caráter descritivo. A coleta de dados foi realizada por meio de entrevistas a partir de um roteiro semiestruturado e grupo focal, contando com nove alunos. Os dados coletados e analisados evidenciam que a indisciplina é vista pelos participantes como manifestação de desrespeito de maneira geral e exige uma intervenção da escola em relação a esse tipo de comportamento. Dentre as principais causas foram assinaladas a imaturidade e desinteresse do aluno. Verificou-se também a necessidade de regras na escola e a evolução do senso crítico, visando o desenvolvimento da autonomia dos estudantes. Palavras-chave: Indisciplina, Ensino-aprendizagem, Ensino médio.
\end{abstract}

* Egressa do Programa de Pós-graduação em Educação (PPGEd) - Mestrado em Educação da Universidade do Oeste de Santa Catarina - Unoesc - Campus de Joaçaba - SC. O artigo apresentado constitui parte das discussões da dissertação "Um olhar sobre o processo de ensino e aprendizagem no Instituto Federal Catarinense - IFC - Campus Videira: interfaces com a indisciplina escolar no ensino médio integrado", sob orientação da Profa. Dra. Maria Teresa Ceron Trevisol. 


\title{
LEARNING AND TEACHING IN MIDDLE SCHOOL: INTERFACES WITH THE SCHOOL INDISCIPLINA
}

\begin{abstract}
The present work aims to analyze the understanding of the students of integrated high school, from a federal educational institution, about the indiscipline phenomenon in the school context. The research is characterized as exploratory, of a qualitative nature, of descriptive character. The data were collected through interviews from a semi-structured script and a focal group, with 9 students. The data collected and analyzed shows that indiscipline is seen by the participants as a demonstration of disrespect in a general way and that is necessary a school intervention in relation to these attitudes. The main causes include the immaturity and the lack of interest from the student. There is a necessary rules at school and the development of greater critical sense for the development of student's autonomy.
\end{abstract}

Key-words: Indiscipline, Teaching-learning, High school.

\section{INTRODUÇÃO}

Refletir a respeito das práticas pedagógicas que permeiam os espaços escolares, do processo de aprendizagem e dos aspectos que nele interferem, como é o caso das manifestações de indisciplina constituem tarefa inerente aos profissionais da educação. Nesse sentido, é necessário trazer o entendimento dos atores (alunos, professores, gestores e equipe técnica) sobre essas questões, pois, caso contrário, em situações que demandam mudanças ou tomada de encaminhamentos envolvendo esses procedimentos corre-se o risco de tomar decisões com visão polarizada, ou seja, que leva em conta apenas alguns fatores em detrimento de outros. O recorte proposto nesse texto evidencia o entendimento e vivência do aluno a respeito do processo de aprendizagem no ensino médio e a interferência da indisciplina nesse contexto. Constata-se que em muitos momentos o posicionamento dos alunos tem sido deixado de lado; entretanto, a compreensão da situação nos traz informações indispensáveis 
para pensar o sistema de ensinar-aprender e o encaminhamento de problemas do cotidiano escolar.

Em face desse panorama, esse texto visa analisar a compreensão dos estudantes do ensino médio integrado de uma instituição federal de ensino a respeito do fenômeno da indisciplina, considerando fundamental sua relação com a forma de ensinar e aprender nos dias atuais. Buscou-se identificar, também, os principais aspectos que colaboram para a compreensão das questões relacionadas à indisciplina na escola.

A base empírica desse texto é uma investigação realizada no decorrer do Curso de Mestrado em Educação e que focou sobre os processos de ensino e aprendizagem no Instituto $\mathrm{Fe}$ deral Catarinense IFC - Campus Videira. A pesquisa realizada se caracteriza como de cunho exploratório, de natureza qualitativa, de caráter descritivo. A coleta de dados foi efetivada por meio de entrevistas a partir de um roteiro semiestruturado e grupo focal, contando com um total de nove alunos do ensino médio integrado dos três cursos técnicos que a instituição oferece. O próprio espaço escolar foi utilizado para a coleta de dados. Durante aproximadamente duas horas, em uma sala de aula, nas dependências do IFC os estudantes puderam dialogar e refletir sobre o tema proposto. A análise dos dados buscou considerar os elementos trazidos pelos sujeitos a partir da técnica de análise de conteúdo, o que possibilitou nos aproximarmos do posicionamento dos alunos a respeito da temática da pesquisa.

A indisciplina tem sido identificada como uma das maiores dificuldades encontradas nos dias atuais em nossas escolas, assim como na instituição objeto deste estudo, seja pelas exigências que o mundo moderno nos impõe, especialmente com a presença das tecnologias na vida das pessoas, em que um quadro negro e giz não são mais suficientes para tornar uma aula atrativa e interessante aos alunos, ou, devido aos diversos contextos (familiar, social, entre outros) que envolvem as pessoas que constroem a realidade dos alunos. 


\section{ENSINO - APRENDIZAGEM E A INDISCIPLINA NO CONTEXTO ESCOLAR: DESAFIOS E POSSIBILIDADES}

O processo de ensino-aprendizagem é um dos aspectos mais discutidos no âmbito educacional. No ato de ensinar e aprender podem ser considerados procedimentos que envolvem diversos atores: professor, aluno, equipe pedagógica, família, entre outros, além de diferenciados aspectos do ambiente escolar, dentre eles: recursos disponíveis, cultura escolar, motivação, expectativas, entre outros. Tal procedimento torna-se desta forma uma ação complexa e que exige olhares atentos dos profissionais que ali atuam frente às demandas apresentadas.

Dentre os objetivos propostos no âmbito escolar verifica-se o desenvolvimento de saberes desde a fase de alfabetização na infância até conceitos ligados à Sociologia e Filosofia no ensino médio, visando à formação integral do estudante que futuramente será inserido no mundo do trabalho. Desde muito cedo o jovem convive e necessita enfrentar as demandas da sociedade atual em que a lógica mercadológica está cada vez mais em evidência, em detrimento dos valores humanos. Entendendo a educação como processo de transformação social a partir da emancipação dos indivíduos, pensar a qualidade do ensino remete à defesa radical da cidadania que, experimentada na escola, pode refletir numa sociedade mais justa e igualitária (SILVA, 2009; PATTTO, 1999). Assim, não se pode considerar suficiente o acesso e a permanência do estudante se ele não obtiver êxito nos estudos - cabe à escola oferecer a ampliação das oportunidades educacionais, assim como a difusão dos conhecimentos e sua elaboração crítica com vistas à elevação cultural e científica do jovem (LIBÂNEO, 2012).

Experiências de fracasso escolar, conhecidas ou compreendidas como dificuldades de aprendizagem, desmotivação, inabilidade para os estudos, em grande parte das situações estão relacionadas com a indisciplina na escola, considerando que a desordem tem sido definida e compreendida principalmente como um descompromisso dos estudantes com a instituição educacional, gerando a famosa bagunça em sala de aula, violên- 
cia, depredação, entre outros. Ao analisarmos de maneira mais profunda as questões envolvendo a indisciplina nesse contexto não podemos deixar de considerar o papel da instituição educacional como também promotora dessas questões bem como analisar em que medida ela tem contribuído para a manutenção de práticas dessa natureza nos alunos. Nesse sentido, estamos em consonância com o posicionamento de Fleuri (2008) quando enfatiza que devemos nos questionar como a escola tem induzido o comportamento submisso, mecânico e individual em detrimento da formação de pessoas livres, criativas e solidárias. Assim, indaga-se: as manifestações de indisciplina pelos alunos devem ser compreendidas como aversão ou chamada de atenção dos sujeitos envolvidos no processo escolar?

Para um ambiente favorável de aprendizagem é importante considerar um mínimo de cooperação entre os pares e profissionais que atuam nesse contexto, no sentido do respeito e ajuda mútua, assim, considera-se determinados limites dentro do espaço escolar que representam uma certa ordem, porém, já estamos em tempos de abertura e diálogo entre profissionais e alunos para que essa "ordem" não seja imposta e sim construída pela coletividade. Buscar compreender e definir os fenômenos que permeiam o espaço escolar e o comportamento de muitos discentes pode favorecer a melhoria dos processos oportunizados nesse contexto. À luz de alguns autores como Cunha (2009) tem-se que a indisciplina é relacionada a vários fatores como motivação, comportamento e aprendizagem, assim como ao desinteresse do aluno. $\mathrm{O}$ autor nos traz que os próprios estudantes são mais diretivos e definem como comportamento inadequado o não parar quieto, bagunçar, entre outros - ou seja, indisciplinado é quem que atrapalha o andamento das aulas. Na visão de Becker (1977), indisciplinado é o transgressor, aquele que passa a ser percebido como tal pela não conformidade com as regras criadas por grupos sociais nos quais se insere. Nesse sentido, podemos refletir sobre a maneira como estamos percebendo e atuando sobre essas questões.

O disciplinamento teorizado por Foucault (1977) constitui aspecto relevante que é observado em pesquisas recentes e 
especificamente no cotidiano escolar que demonstra a presença de mecanismos disciplinadores com a função de "enclausurar corpos" para favorecer o seu controle. Dinalli e Ferrari (2012) analisam o modelo de escola atual e sua influência na subjetividade discente e consideram o poder disciplinador em sua forma sutil, porém efetiva. A organização do espaço, as hierarquias, a vigilância, tudo isso ainda submete a todos, a um conjunto de normas visando a manutenção da ordem. Assim, o aluno que em muitos momentos se manifesta contrariado, angustiado e descontente, é considerado indisciplinado.

A manifestação do educando tem revelado uma busca por alternativas de quem se sente boicotado em sua autonomia, de quem anseia pela construção do conhecimento, mas em muitos momentos sua participação se torna nula num processo excludente. Oportuno ressaltar que medidas adequadas - como discussões no âmbito educacional, abertura para novas metodologias de ensino, avaliação dos currículos e dos mecanismos pedagógicos entendidos como métodos utilizados em sala de aula, recursos pedagógicos, além do modo de resolver as questões interpessoais entre alunos e professor-aluno - podem favorecer uma práxis mais democrática.

Para Lopes e Gomes (2012, p.274), o currículo é um dos principais aspectos da estrutura escolar que influencia em sala de aula devido à diversidade da realidade dos alunos. O currículo escolar como tem sido produzido e utilizado está distante da realidade dos estudantes, seja pela característica de cientificidade ou mesmo por não considerar as diversas regiões doe um país, ou mesmo a individualidade do aluno. Assim, professores e coordenadores pedagógicos/supervisores são chamados à responsabilidade de enriquecê-lo com os temas atuais e locais e de acordo com a aprendizagem da turma e de cada aluno, planejando e executando atividades viáveis e atrativas, tornando-o significativo. Caso contrário, será cada vez mais comum, vermos alunos desmotivados, desinteressados e insatisfeitos, sendo que estes sentimentos de insatisfação muitas vezes, se manifestam como o comportamento considerado indisciplinado. Sabemos que o professor assume papel determinante, porém, são várias as 
questões relacionadas desde a formação, onde temos diferenças gritantes de nível de escolaridade e formação dos profissionais de uma escola para outra, muitas vezes de uma turma para outra na mesma escola, além disso, recursos pedagógicos escassos, desvalorização dos profissionais, dentre outros fatores que interferem no dia a dia da sala de aula.

Além disso, são diversos os fatores que podem influenciar o comportamento dos jovens e que acabam por refletirem no espaço escolar, dentre os quais podemos citar aspectos familiares, psíquicos e sociais. Na percepção de Boarini (2013), os conflitos são próprios à natureza humana independente da faixa etária ou classe social, embora sejam mais comuns na juventude. Nesse sentido, o autor destaca os condicionantes históricos e sociais ligados ao aluno, como a escola e a família.

Independente da origem social ou das características pessoais dos alunos a escola precisa pensar práticas inclusivas e democráticas, mas sem desconsiderar a importância das regras para a boa convivência nesse âmbito, pois é comum entre os próprios alunos a demanda por uma organização escolar pautada em limites e regras que favoreçam o desenvolvimento da aprendizagem. Assim contata-se a ocorrência de uma espécie de jogo entre submissão e transgressão, poder e resistência, ataque e contra-ataque, geralmente como acontece muitas vezes quando há presença de rigidez de regras. Resta então o prejuízo - individual e coletivo.

Esta linha de pesquisa nos remete a Fleuri (2008), para quem interpretar o poder-saber-disciplinar leva à necessidade de se buscar na educação algo para além das relações puramente disciplinares. Dito em outras palavras, os atores envolvidos no âmbito escolar, como professores e demais profissionais da educação e aluno, são mais do que vigilantes e vigiados, senhores e súditos. São sujeitos que, em cooperação, podem desenvolver relações positivas, criativas e superar os moldes disciplinares à medida que valorizam os dois extremos da relação no melhor que cada um possa oferecer, no sentido afetivo, cognitivo e decisório.

À medida que os conteúdos escolares passem a adquirir significado e estejam mais próximos à realidade dos alunos, assim 
como o diálogo crítico possa fazer parte do cotidiano escolar sem ser percebido como rebeldia, é possível que se inicie um processo de superação dos mecanismos disciplinares, promovendo um processo de aprendizagem significativo, em que o aluno possa opinar sobre os conteúdos que deseja aprender ou na maneira de fazê-lo. Práticas coercitivas aumentam a insegurança e o clima de desrespeito e tendem a gerar cada vez mais comportamentos indisciplinados. Torna-se evidente a urgência da abertura ao diálogo e da construção de relações interpessoais que valorizem o respeito, a boa convivência e visem a melhoria do ambiente escolar que, como consequência, terá relações mais produtivas em termos de aprendizagem significativa e desenvolvimento humano.

\section{ANÁLISE E DISCUSSÃO DE DADOS DE PESQUISA}

Dentre os objetivos propostos nesse texto enfatiza-se, na sequência, a análise de alguns dos dados coletados com a pesquisa que serve de base empírica.

Ao buscarmos estabelecer uma relação entre a indisciplina e a aprendizagem no espaço escolar evidenciamos que dentre os participantes o entendimento é que esta se evidencia em sala de aula especialmente relacionada aos aspectos como o relacionamento interpessoal, participação e postura do aluno, ao xingar o colega, interromper o professor, entre outros. Para eles, o desrespeito em relação aos professores, colegas e demais servidores é tratada como a principal manifestação de indisciplina.

Os discentes apontam ainda atitudes, como violência, conversa, uso de palavrões:

[...] Desrespeito com o professor (AB).

[...] Não só com o professor, mas com os colegas também (AD). [...] a questão das mulheres que limpam as salas, já deu algumas confusões com alguns alunos que não respeitam elas, então, eu acho que isso tbém deveria ser cobrado pelo CGAE (AF).

[...] Atrapalhar as aulas, só pq vc não quer prestar atenção na aula, não deixar a pessoa do lado que quer aprender, não deixar ela prestar atenção, ficar conversando (AC). 
[...] palavrões que os professores escutam e baixam a bola né, não tomam uma atitude diante disso (AD). (Informações verbais).

Observa-se nas atitudes citadas pelos alunos que, em sua grande maioria eles se referem a situações que acontecem em sala de aula e novamente esperam uma cobrança externa no sentido de corrigir o comportamento. A implantação de normas que gerem um ambiente de aprendizagem e de colaboração em geral é esperada no espaço escolar. Martins (2013, p. 11) aponta para a necessidade de um referencial aceito conscientemente por todos, determinando o limite que a liberdade dos outros impõe sobre a liberdade do indivíduo. Tais normas devem ser coerentes com o processo educativo e precisam ser claras e justificadas, além do fato de que o seu cumprimento é exigido por toda a comunidade escolar.

Ao analisar a questão Costa (2012), assim como outros estudiosos, chama atenção para a indisciplina no cotidiano escolar, na medida em que ela é encarada como algo que perturba a ordem no ambiente educacional. Assim, face a desordem é comum o entendimento por parte dos entrevistados, de que a realização dos objetivos da escola somente se mostra possível a partir da subordinação dos alunos às normas. Isso é possível perceber quando os estudantes parecem solicitar uma maior cobrança e rigidez por parte da escola.

Quanto aos motivos que levam os alunos a cometer atos tidos como indisciplinados, eles apontam justificativas diversas que vão desde a falta de interesse do educando, número de horas diárias que necessitam permanecer na instituição, a imaturidade, a cobertura dos amigos; ou seja, quando acontece algo os colegas se protegem, falta de punição e controle, além da influência familiar:

[...] Como eu tinha dito mesmo, sendo 8 horas, mais de 8 horas, 10 horas por dia

[...] dentro de uma instituição fechado aqui, a pessoa se ela não tiver uma maturidade muito grande vai ser complicado manter a disciplina, manter a linha durante todo esse tempo (AA). 
[...] a gente recebe um livro com muitos regulamentos, mas quando o aluno entre aqui, ele pode fazer [...] como posso dizer? as atitudes dele não são cobradas pelas autoridades maiores do instituto (AF).

[...] Acho que vem um pouco de criação de casa (AC). (Informações verbais).

Como se vê, entre os fatores apontados observam-se aspectos ligados ao aluno, como o desinteresse, imaturidade, família e outros ligados à instituição, como a falta de cobrança e punição. Em relação aos encaminhamentos e resolução das situações que envolvem a indisciplina no ambiente escolar, verificou-se a necessidade da cobrança e encaminhamento para instâncias extraclasse, contando com o apoio do regulamento disciplinar, por exemplo.

Relevante esclarecer que o regulamento disciplinar é um documento que norteia a postura do aluno dentro da instituição e prevê situações cotidianas, das mais leves às mais graves. Segundo Boarini (2013, p. 128), a presença das normas favorece a caracterização de um desvio. Quando há ausência do comportamento delimitado que se espera socialmente ou no ambiente escolar: "são as normas estabelecidas pela família, pela escola ou pela sociedade em geral, em determinados momentos históricos, que atribuem o significado do comportamento disciplinado ou indisciplinado. "Assim, a possibilidade de o aluno ser cobrado e advertido de acordo com o regulamento escolar, cria a expectativa que essa seria a melhor opção, sempre que surgirem dificuldades. De algum modo pode estar faltando incluir práticas democráticas e construtivas de resolução de conflitos e dificuldades em sala de aula e por outro lado, pode não estar sendo estabelecido um limite necessário em relação à postura do aluno, ou seja, faz-se necessária uma postura mais objetiva do professor no recinto.

No entendimento de Dinalli e Ferrari (2012), a disciplina/a aplicação de regras pode ser considerada o poder em sua forma mais sutil e efetiva. A observação constante favorecida pela organização do espaço garante também o monitoramento e 
controle dos indivíduos. Predomina uma hierarquia, por meio da qual os superiores vigiam os subalternos e a censura obriga todos a se adaptarem às normas. Esse modelo educativo predominou durante muito tempo e hoje se faz presente nas escolas de modo mais sutil. Não podemos negar a existência de uma estrutura física nos moldes da limitação do fluxo dos alunos, horários, currículo, entre outros aspectos.

Assim, o cumprimento das normas de conduta é critério para a possibilidade de integração ou mesmo aceitação do sujeito no espaço escolar. A autoridade moral exercida por quem faz as normas e as executa exerce uma força ética legitimada coletivamente e que permite a repressão de quem viola as regras (COSTA, 2012, p. 8). O indivíduo muitas vezes não tem consciência dessa dinâmica.

A demanda por uma organização escolar pautada em limites e regras é percebida por Souza, Queiroz e Menandro (2010, p. 535) que desenvolveram uma pesquisa com jovens sobre autonomia e vida escolar. Os pesquisadores puderam observar que a expectativa dos alunos está relacionada com o seu futuro, com questões profissionais e de sucesso. Esse público se inquieta com a ausência de regras e exigência por parte da escola. Para os pesquisadores, o pedido por mais regras e disciplina pode ser interpretado como uma solicitação para manter a possibilidade de uma adolescência ideal "normal"; os jovens querem ser preparados, querem condições, algo que lhes garanta um caminho de sucesso. Ou seja, talvez o momento em que surgem situações disciplinares seja a ocasião de levar o aluno a considerar aspectos de sua formação que envolvem uma reflexão sobre o coletivo e suas relações.

Essa necessidade se tornou evidente no grupo de estudantes pesquisados, pois ao serem levados a pensar se o comportamento indisciplinado pode estar relacionado a uma dificuldade eles discordaram em sua maioria. Os mesmos reafirmam que a postura assumida pelo aluno na escola ou diante do aprendizado está relacionada ao seu interesse; assim, se ele está conversando, disperso, é por não estar interessado na aula por algum motivo, mas não tem, necessariamente, a intenção de atrapalhar: 
[...] acaba dispersando, e dispersando ele começa a conversar de assuntos mais interessantes com o colega (AA).

[...] muitas vezes tem, tem a ver sim, da pessoa não gostar e fazer pq quer mesmo, pra irritar mesmo (AD). (informações verbais).

Eles consideram que em algum momento a indisciplina pode representar uma manifestação de descontentamento e algo intencional do discente. Complementam que mesmo o aluno tendo alguma dificuldade ou esteja passando por algum problema isso não pode ser usado como desculpa para seu comportamento.

Apesar de apresentarem a manifestação e a participação do aluno como necessárias, assim como ser ouvido e compreendido, os entrevistados discordam que as limitações dos colegas podem levar a manifestações vistas como indisciplinadas. Essas atitudes são entendidas pelos alunos como incompatíveis com o ambiente escolar e acabam por prejudicar o processo de ensino e aprendizagem, refletindo uma lógica que visa o desempenho e não identifica as diferenças individuais.

A escola está inserida em um contexto social e este nos ajuda a interpretar o que acontece nela. Desconsiderar estes fatores pode refletir diretamente em toda a cominidade escolar, o individualismo presente na sociedade atual. Segundo Boarini (2013, p. 126), o homem moderno estaria se interessando pouco ou mesmo se abstendo da participação e da preocupação com o coletivo, o que envolve pensar o outro. As atenções estariam cada vez mais se voltando para o que é pessoal, ou seja, "no individualismo contemporâneo, a impessoalidade converteu-se em indiferença [...]", assim, situações de desrespeito ou desinteresse pelas dificuldades dos demais são comuns e aceitáveis.

Nesse sentido, aspectos que dizem respeito ao aluno em sua particularidade recebem evidência, enquanto fatores como a motivação e o respeito às normas passam a ser percebidos como inerentes ao mesmo, ou seja, considera-se que o estudante se manifesta de tal forma devido a aspectos que dizem respeito exclusivamente a questões individuais, como origem familiar, por exemplo. 


\section{CONCLUSÕES}

Considerando o objetivo desse artigo, que buscou analisar as questões disciplinares e sua interferência nos processos de aprendizagem, verificou-se que a indisciplina é definida dentre os estudantes como atitudes de desrespeito e que geram consequências para o processo de ensino e aprendizagem. Aspectos que envolvem a relação com o outro e com o espaço da escola - como chacotas, violência, riscar parede, dentre outros - foram destacados pelos entrevistados. O papel do professor, assim como de ações externas ao espaço da sala de aula, é considerado como fundamental para minimizar essas situações. Assim, evidenciou-se que dentre os estudantes é esperado que as regras existentes na escola sejam cumpridas por todos, e se isso não acontecer alguma medida precisa ser tomada.

Em relação às causas dos comportamentos considerados indisciplinados os estudantes destacaram a elevada carga horária diária estudantil que estaria gerando procedimentos descomedidos. Além disso, aspectos pessoais como a imaturidade e questões familiares foram também mencionados, ou seja, a indisciplina teria origem na postura individual do aluno. Uma terceira causa seria a ausência de punição por parte da escola quando as situações acontecem.

Assim, a indisciplina estaria ligada ao desinteresse do aluno em relação ao aprendizado; ela não é percebida como uma manifestação que pode refletir dificuldade. Nesse sentido, ainda é identificada como uma forma de rejeição às normas presentes no contexto escolar.

Verificou-se nas respostas dos pesquisados a importância das regras, sendo o cumprimento delas esperado pela maioria dos estudantes, porém eles entendem que grande parte delas surge de maneira imposta e torna-se pouco efetivas. A busca pelo desenvolvimento dos estudantes poderia ser favorecida se as normas fossem pensadas coletivamente - porém esse aspecto não foi observado ou questionado pelos participantes, que demonstraram certa ausência de senso crítico.

O diálogo entre os profissionais e alunos sobre os objetivos a que a escola se destina e o repensar sobre como serão 
conduzidos os processos de aprendizagem - contando com o apoio dos diferentes segmentos que fazem parte da instituição, incluindo coordenações, direção e equipe de apoio pedagógico - tornaram-se evidente. Da mesma forma, medidas a serem adotadas em relação ao comportamento indisciplinado são vistas como ineficientes pelos alunos e não proporcionam um ambiente onde prevaleçam relações de maior proximidade, abertura, troca, respeito às diferenças e desenvolvimento de senso crítico. É fundamental que medidas disciplinares sejam compreendidas e aceitas pela comunidade escolar como possíveis para um ambiente mais construtivo no sentido da maior autonomia, desenvolvimento profissional e humano.

\section{REFERÊNCIAS}

BECKER, Howard S. Uma teoria da ação coletiva. Rio de Janeiro: Zahar Editores, 1977.

BOARINI, Maria Lucia. Indisciplina escolar: uma construção coletiva. Revista semestral da Associação Brasileira de Psicologia Escolar e Educacional, São Paulo, v. 17, n. 1, p. 1123-1131, jan/jun. 2013. Disponível em: <www. scielo.com>. Acesso em: 10 ago. 2014.

COSTA, Dautarin Bruno Monteiro da. A escola e a indisciplina: partindo de um caso rotulado. Dissertação (Mestrado em Sociologia)-Instituto Universitário de Lisboa: Lisboa, 2012.

CUNHA, Maria de Fátima Pires Carneiro da. Indisciplina e a noção de justiça em adolescentes escolares. Educar, Curitiba: Ed. UFPR, n. 35, p. 197-210, 2009. Disponível em: <www.scielo.com>. Acesso em: 10 maio 2014. DINALI, Wescley; FERRARI, Anderson. Herança moderna disciplinar e controle dos corpos: Quando a escola se parece com uma "gaiola". Educação em Revista, Belo Horizonte, v. 28, n. 2, p. 393-422, jul. 2012. Disponível em: <www.scielo.com>. Acesso em: 01 set. 2014.

FLEURI, Reinaldo Matias. Entre disciplina e rebeldia na escola. Brasília, DF: Liber Livro Editora, 2008. 124 p.

. Educar para quê? contra o autoritarismo da relação pedagógica na escola. 9. ed. São Paulo: Cortez, 2001. 110 p.

FOUCAULT, Michel. Vigiar e Punir: Nascimento da prisão. Tradução Ligia M. Pondé Vassalo. Petrópolis: Vozes, 1977. 208 p.

LIBÂNEO, José Carlos. Democratização da escola pública: a pedagogia crítico-social dos conteúdos. 27. ed. São Paulo: LOYOLA, 2012.

LOPES, Rosilene Beatriz; GOMES, Candido Alberto. Paz na sala de aula é uma condição para o sucesso escolar: que revela a literatura. Aval. pol. 
publ. Educ., Rio de Janeiro, v. 20, n. 75, p. 261-282, abr./jun. 2012. Disponível em: <www.scielo.com>. Acesso em: 06 set. 2014.

MARTINS, Ernesto Candeias. A interface entre o papel da escola e a (In) disciplina escolar. 2013. Disponível em: <www.scielo.com>. Acesso em: 12 jul. 2014.

PATTO. Maria Helena Souza. A produção do fracasso escolar: histórias de submissão e rebeldia. São Paulo: Casa do psicólogo, 1999.

SILVA, Maria Abádia da. Qualidade social da educação pública: algumas aproximações. Cad.CEDES, Campinas, v.29, n.78, p.216-226, Aug. 2009.

SOUZA, Luiz Gustavo Silva; QUEIROZ, Silvio Silveira de; MENANDRO, Maria Cristina Smith. E quando os estudantes pedem mais disciplina? Estudo de caso e reflexões sobre autonomia e vida escolar. Rev. Psicologia Ciência e Profissão, v. 30, n. 3, p. 524-539, 2010. Disponível em: <www.scielo. com>. Acesso em: 06 set. 2014.

Sobre os autores

Mini-currículo:

Danieli Vieceli: Mestre em Educação pela Universidade do Oeste de Santa Catarina - Unoesc Campus Joaçaba. Especialista em Gestão de Recursos Humanos pela Universidade Federal do Paraná. Psicóloga pela Universidade do Oeste de Santa Catarina- Unoesc Campus Joaçaba. Atua no IFC - Videira (SC). E-mail: danieli.vieceli@ifc.edu.br

Maria Teresa Ceron Trevisol: Doutora em Psicologia Escolar e do Desenvolvimento Humano pelo Instituto de Psicologia da Universidade de São Paulo - USP. Docente da graduação e do Programa de Pós-graduação em Educação (PPGEd) da Universidade do Oeste de Santa Catarina - Unoesc - Campus de Joaçaba (SC). E-mail: mariateresa.trevisol@unoesc.edu.br 